\title{
Influencing Factors of Professional Commitment of Students Enrolled in Broad Categories
}

\author{
Jinmei TIAN ${ }^{1}$, Yimin $\mathrm{WU}^{2}$, and Wene $\mathrm{QI}^{2}$ \\ ${ }^{1}$ School of Economics and Management, Shanghai Polytechnic University \\ Shanghai, China \\ ${ }^{2}$ College of Economics and Management, South China Agricultural University \\ Guangzhou, China
}

\begin{abstract}
The authors surveyed students enrolled in broad categories to evaluate college general enrollment performance (professional commitment, professional involvement) and study its determinants (professional diversion fairness, professional satisfaction). Data analysis results revealed that information fairness, procedural fairness, and teaching satisfaction all have significant positive impacts on ideal commitment, continuous commitment, and professional involvement. Finally the authors put forward suggestions for professional diversion to improve students' professional commitment and involvement.
\end{abstract}

Keywords-Enrollment in broad categories; Professional diversion fairness; Professional satisfaction; Professional commitment; Professional involvement

\section{INTRODUCTION}

"Enroll students in broad categories of majors" has become the main trend of university enrollment for talent cultivation mode reform in China, which is aimed to improve talent cultivation quality. Currently, enrollment in large categories in Chinese universities mainly has three modes: Enrollment as per disciplines (such as business administration, and mechanical type), "teaching base class" and and professional diversion after the general education.

Bin WU, Yuhong JIN (2011) summarized the ten advantages of general enrollment. But up to now, little research was found on performance evaluation from the perspective of students enrolled in broad categories, not to mention empirical research. On the basis of qualitative interview, this research surveyed students of certain Chinese southern university enrolled in broad categories one year after their professional diversion, to explore their professional commitment and professional involvement situation and their influencers like professional diversion fairness, course setting satisfaction and teaching satisfaction, and provide practical and feasible suggestions for enrollment in broad categories talent cultivation mode.

\section{LITERATURE REVIEW AND RESEARCH HYPOTHESIS}

\section{A. Service fairness}

Fairness concept is originated from social psychology, and service fairness theory is developed on the basis of social exchange theory and social comparison theory. Austin (1979) pointed out that, the fairness here not only included distributive fairness, but also procedural fairness, which gained recognition (Bowen, Gilliland and Folger, 1999) and empirical support (Clemmer and Schneider, 1996) from scholars afterwards. Currently, academic scholars have reached consensus on the four components of service fairness, which is information fairness, procedural fairness, interactional fairness, and distributive fairness. Based on our qualitative interview result, information fairness and procedural fairness are more related to the professional diversion situation than the other two kinds of fairness, so this research merely studies the influence of these two types of fairness on professional commitment and professional involvement. Information fairness refers to the degree of fairness, truth, reliability and completeness of information provided by service-oriented enterprises to customers with suitable mode within suitable time (Greenberg, 1993; Xie and Han, 2007), and in this research, it refers to the degree of fairness, reality, reliability and integrity about the relevant information provided by the college to students; Procedural fairness refers to customers' valuation on service process' fairness (Austin, 1979; Leventhal, 1980); in this research, it refers to $t$ students' evaluation on whether the professional diversion policies and procedures formulated by the college are fair. In case that the information acquired by students in professional diversion is complete and reliable, the professional diversion policies and programs are fair, and the easier it will be for them to choose the major that can match with their dreams, interests and capacities, and the higher their professional commitment (ideal commitment and continuous commitment) their professional involvement will be. Thus, the following hypothesis was developed:

H1a: Information fairness has a positive influence on students' professional ideal commitment;

H1b: Information fairness has a positive influence on students' professional continuous commitment; 
H1c: Information fairness has a positive influence on students' professional involvement;

H2a: Procedural fairness has a positive influence on students' professional ideal commitment;

$\mathrm{H} 2 \mathrm{~b}$ : Procedural fairness has a positive influence on students' professional continuous commitment;

H2c: Procedural fairness has a positive influence on the professional involvement of students.

\section{B. Professional satisfaction}

Professional satisfaction is the perception and emotional reaction of students for their choice major. The qualitative research result identified two dimensions of professional satisfaction: Course setting satisfaction and teaching satisfaction. Professional satisfaction is the overall opinion and emotional reaction for professional learning and life, which is closely related to their behavior enthusiasm. Students who are satisfied with the course setting and teaching show high interests in their major with full of hopes for the major' future, so their professional ideal commitment, continuous commitment and professional involvement are all high. Thus, it is assumed that:

H3a: Course setting satisfaction is positively related to the students' professional ideal commitment;

H3b: Course setting satisfaction is positively related to the students' professional continuous commitment;

H3c: Course setting satisfaction is positively related to the students' professional involvement;

H4a: Teaching satisfaction is positively related to the students' professional ideal commitment;

H4b: Teaching satisfaction is positively related to the students' professional continuous commitment;

H4c: Teaching satisfaction is positively related to the students' professional involvement;

\section{Professional commitment}

The concept of professional commitment is originated from the relevant research about organization commitment and career commitment. The organizational commitment is put forward by American Sociologist Becker (1960), which reflects the psychological relationship between organization members and the organization. Allen and Meyer (1990) proposed the three-factor model that is widely accepted at present, i.e., emotional commitment, normative commitment and continuous commitment. LIAN et al. (2005) found out a new dimension of career commitment except for the three dimensions, which they named by ideal commitment. Emotional commitment mainly reflects the emotions and wishes of college students for their learned major, while continuous commitment mainly reflects the wishes of college students to keep the major learning due to personal qualification, capacity, employment opportunities, as well as salary and other economic consideration; normative commitment refers to students keep learning their major due to obligations and responsibilities; ideal commitment reflects that college students think that their major can help them to realize their dreams and ambitions.

According to the investigation result of Wei ZHANG at al. (2014) about the college students in Ningbo, the overall level of professional commitment for college students under general enrollment cultivation mode wasn't high, of which continuous commitment ranks the first, emotional commitment ranks the last among the four dimensions, while ideal and normative commitments ranked in the middle. For their professional choice standard, they firstly consider salary, promotion opportunities and other factors. In this research, we have focused on discussing the current status about professional ideal commitment and continuous commitment of students under the cultivation mode of enrollment in broad categories as well as the influence on professional involvement. We think that, enrollment in broad categories provides enough time for students to understand and select majors, and the opportunity to hear professional introduction, consultation, and attending class trial; college students are more likely to select their recognized and favored major that can match with their strengths and ideals; Once the major is selected, the bigger the possibility will be for them to stick to it, and they are more willing to work hard and enthusiastically in the professional learning process showing active learning attitude and learning behaviors. Thus, it is assumed that:

H5: Professional ideal commitment has a positive influence on students' professional continuous commitment;

H6: Professional ideal commitment has a positive influence on students' professional involvement;

H7: Professional continuous commitment has a positive influence on students' professional continuous commitment.

On the basis of literature review, qualitative interview and reasoning, this study proposed the following conceptual model.

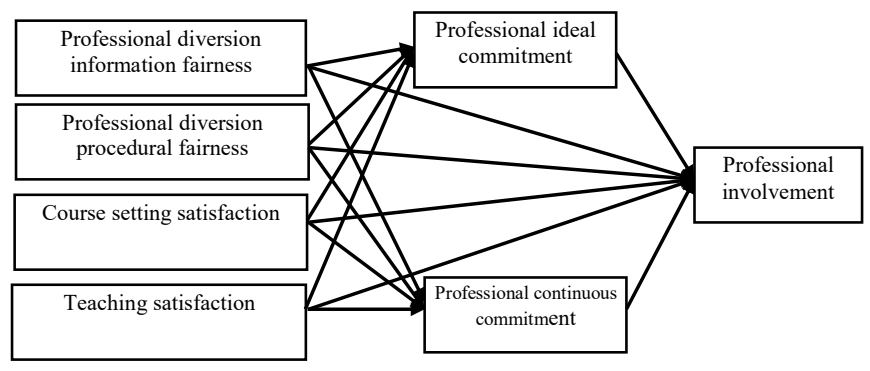

Fig. 1. Conceptual model

\section{RESEARCh DESIGN AND DATA ANALYSIS}

\section{A. Overview of samples}

350 Junior students among three colleges of certain university in South China were suveyed one year after their professional diversion, and 334 valid questionnaires are retuned with a $95.43 \%$ response rate, including 146 males and 188 females which occupy $43.7 \% \%$ and $56.3 \% \%$ respectively. 


\section{B. Variable measurement and descriptive statistics}

Information fairness and procedural fairness scale were designed referring to the service fairness scale of XIE and HAN (2007) in combination with the professional diversion characteristics of enrollment in broad categories; Course setting satisfaction and teaching satisfaction scale were designed based on the qualitative interview result, TIAN (2011) and other reserchers' teaching capacity scale; Professional ideal commitment, continuous commitment and professional involvement scale are designed on the basis of the professional commitment scale of LIAN et al. (2005), the customer involvement theory, and enrollment in broad categories situation. Using SPSS 20.0, we conducted exploratory factor analysis, eliminateing items with less than 0.5 factor loadings and cross loadings, then analyze the reliability of variables; except the professional involvement for which the internal consistency factor is beyond 0.651 , the internal consistency factor for the rest variables is within the range of $0.788-0.903$ (refer to Table 1), which can indicate that the measurement of all variables has high reliability.

TABLE I. DESCRIPTIVE STATISTICS AND ReLiability ANALysis

\begin{tabular}{|c|c|c|c|c|}
\hline Variable name & Item number & Mean value & Standard deviation & Cronbach $\alpha$ \\
\hline Information fairness & 5 & 3.921 & 1.114 & 0.841 \\
\hline Procedural fairness & 5 & 4.159 & 1.109 & 0.799 \\
\hline Course setting satisfaction & 5 & 3.970 & 1.018 & 0.835 \\
\hline Teaching satisfaction & 6 & 4.596 & 0.976 & 0.903 \\
\hline Professional ideal commitment & 7 & 4.543 & 1.095 & 0.902 \\
\hline Professional continuous commitment & 4 & 4.183 & 1.045 & 0.788 \\
\hline Professional involvement & 4 & 4.374 & 1.030 & 0.651 \\
\hline
\end{tabular}

\section{Hierarchical regression analysis}

Using SPSS20.0 software, we take ideal commitment, continuous commitment and professional involvement as dependent variables respectively to conduct hierarchical regression analysis.

In three hierarchical regression analysis models, all the variables are the average value of their items. The maximum value for variance inflation factor (VIF) of all variables is
1.875 , which is far smaller than the clinical value (10.0) stressed by Hale et al., indicating free of serious colinearity issues.

In three hierarchical regression analysis models, gender and colleges entried the model in the firt step as control variables, but all their standardied coefficients are not significant, results following tables only displayed the results of step2 and step3, please refer to Table 2, Table 3 and Table 4.

TABLE II. HIERARCHICAL REGRESSION ANALYSIS RESULT OF PROFESSIONAL IDEAL COMMITMENT AS THE DEPENDENT VARIABLE

\begin{tabular}{|c|c|c|c|c|}
\hline \multirow[b]{2}{*}{ Steps } & \multirow[b]{2}{*}{ Variable } & \multicolumn{3}{|c|}{ Professional ideal commitment } \\
\hline & & $\begin{array}{c}\text { Standardized } \\
\text { Coefficient }\end{array}$ & $\mathrm{T}$ value & Sig \\
\hline \multirow{5}{*}{ Step 2} & Information fairness & .114 & 2.029 & $.043 * *$ \\
\hline & Procedural fairness & .170 & 3.244 & $001 * * *$ \\
\hline & Course setting satisfaction & .110 & 2.024 & $.044 * *$ \\
\hline & Teaching satisfaction & .374 & 7.028 & $000 * * *$ \\
\hline & $\begin{array}{c}\mathrm{R}^{2} / \text { adjusted } \mathrm{R}^{2} \\
\triangle \mathrm{R}^{2} \\
\mathrm{df} 1 / \mathrm{df} 2 \\
\triangle \mathrm{F} / \triangle \mathrm{F} \text { significance }\end{array}$ & \multicolumn{3}{|c|}{$\begin{array}{c}0.366 / 0.355 \\
0.358 \\
4 / 327 \\
46.233 / 0.000^{* *} \\
\end{array}$} \\
\hline
\end{tabular}


TABLE III. HIERARCHICAL REGRESSION ANALYSIS RESULT OF PROFESSIONAL CONTINUOUS COMMITMENT AS THE DEPENDENT VARIABLE

\begin{tabular}{|c|c|c|c|c|}
\hline \multirow[b]{2}{*}{ Steps } & \multirow[b]{2}{*}{ Variable } & \multicolumn{3}{|c|}{ Professional continuous commitment } \\
\hline & & $\begin{array}{c}\text { Standardi } \\
\text { zed } \\
\text { Coeffici } \\
\text { ent } \\
\end{array}$ & $\begin{array}{c}\mathrm{T} \\
\text { value }\end{array}$ & Sig \\
\hline \multirow{5}{*}{$\begin{array}{c}\text { Step } \\
2\end{array}$} & $\begin{array}{l}\text { Information } \\
\text { fairness }\end{array}$ & .101 & 1.724 & $.086^{*}$ \\
\hline & $\begin{array}{l}\text { Procedural } \\
\text { fairness }\end{array}$ & .131 & 2.384 & $.018 * *$ \\
\hline & $\begin{array}{l}\text { Course setting } \\
\text { satisfaction }\end{array}$ & .270 & 4.733 & $.000 * * *$ \\
\hline & $\begin{array}{c}\text { Teaching } \\
\text { satisfaction }\end{array}$ & .190 & 3.406 & $.001 * * *$ \\
\hline & $\begin{array}{c}\text { R2/adjusted } \mathrm{R}^{2} \\
\triangle \mathrm{R}^{2} \\
\mathrm{df1} / \mathrm{df} 2 \\
\triangle \mathrm{F} / \triangle \mathrm{F} \\
\text { significance }\end{array}$ & \multicolumn{3}{|r|}{$\begin{array}{c}0.303 / 0.290 \\
0.284 \\
4 / 327 \\
33.278 / 0.000^{* * *}\end{array}$} \\
\hline \multirow[b]{2}{*}{$\begin{array}{c}\text { Step } \\
3\end{array}$} & $\begin{array}{c}\text { Ideal } \\
\text { commitment }\end{array}$ & .498 & 9.859 & $.000 * * *$ \\
\hline & $\begin{array}{c}\mathrm{R}^{2} / \text { adjusted } \mathrm{R}^{2} \\
\triangle \mathrm{R}^{2} \\
\mathrm{df1} / \mathrm{df} 2 \\
\triangle \mathrm{F} / \triangle \mathrm{F} \\
\text { significance }\end{array}$ & \multicolumn{3}{|r|}{$\begin{array}{c}0.383 / 0.370 \\
0.081 \\
1 / 326 \\
42.713 / 0.000^{* * *}\end{array}$} \\
\hline
\end{tabular}

TABLE IV. HIERARCHICAL REGRESSION ANALYSIS RESULT OF PROFESSIONAL INVOLVEMENT AS THE DEPENDENT VARIABLE

\begin{tabular}{|c|c|c|c|c|}
\hline \multirow[b]{2}{*}{ Steps } & \multirow[b]{2}{*}{ Variable } & \multicolumn{3}{|c|}{ Professional involvement } \\
\hline & & $\begin{array}{c}\text { Standardized } \\
\text { Coefficient }\end{array}$ & $\mathrm{T}$ value & Sig \\
\hline \multirow{5}{*}{ Step 2} & Information fairness & .164 & 2.871 & $004 * * *$ \\
\hline & Procedural fairness & .153 & 2.864 & $004 * * *$ \\
\hline & Course setting satisfaction & 052 & 0.941 & .347 \\
\hline & Teaching satisfaction & .375 & 6.935 & $000 * * *$ \\
\hline & $\begin{array}{c}\mathrm{R}^{2} / \text { adjusted } \mathrm{R}^{2} \\
\triangle \mathrm{R}^{2} \\
\mathrm{dfl} / \mathrm{df} 2 \\
\triangle \mathrm{F} / \triangle \mathrm{F} \text { significance }\end{array}$ & \multicolumn{3}{|c|}{$\begin{array}{c}0.345 / 0.333 \\
0.343 \\
4 / 327 \\
42.795 / 0.000^{* *}\end{array}$} \\
\hline \multirow[b]{3}{*}{ Step 3} & Ideal commitment & .498 & 9.859 & $000 * * *$ \\
\hline & Continuous commitment & .108 & 2.246 & $.025 * *$ \\
\hline & $\begin{array}{c}\mathrm{R}^{2} / \text { adjusted } \mathrm{R}^{2} \\
\triangle \mathrm{R}^{2} \\
\mathrm{df} 1 / \mathrm{df} 2 \\
\triangle \mathrm{F} / \triangle \mathrm{F} \text { significance }\end{array}$ & \multicolumn{3}{|c|}{$\begin{array}{c}0.535 / 0.524 \\
0.190 \\
2 / 325 \\
66.344 / 0.000 * * * \\
\end{array}$} \\
\hline
\end{tabular}

The results show that:

(1) The professional ideal commitment and continuous commitment for students enrolled in broad categories have no significant differences in gender and colleges. Information fairness, procedural fairness, course setting satisfaction, and teaching satisfaction all have significant positive influence on ideal commitment and continuous commitment (only information fairness's effect on the continuous commitment is significant at 0.1 level, while other factors' influence effect are significant at 0.05 or 0.001 level).

(1) The professional involvement of students enrolled in broad categories has no significant differences in gender and colleges. Information fairness, procedural fairness and teaching satisfaction all have significant positive effect on professional involvement at 0.05 level. Course setting satisfaction has an significant positive effect on professional involvement. Ideal 
commitment and continuous commitment have significant positive effect on professional involvement.

\section{CONCLUSIONS AND SUGgestions}

Except for the influence of course setting satisfaction on professional involvement $(\mathrm{H} 3 \mathrm{c})$ was not supported, all the other hypotheses have been supported. Findings of this study have some reference value for the professional diversion of general enrollment, but the research also has some restrictions, such as the sample representativeness need to be improved, and the scales need to be refined. The main findings and suggestions are as follow:

\section{A. Professional diversion fairness influences students' professional commitment and professional involvement}

As can be seen from the hierarchical regression analysis result, information fairness and procedural fairness have significant positive influence on professional ideal commitment, continuous commitment and professional involvement. Thus, it can be seen that professional diversion fairness of the broad categories cultivation mode will directly influence the attitude and behaviors of students for their choosed major.

The professional diversion of general cultivation mode should avoid the disadvantages of soly dependent on entrance examination, and is requested to consider all factors, striving to match professional choice with students' interests, specialties, and dreams, to ensure their professional commitment and high professional involvement. The colleges should provide fair , open and detailed major related information, helping students understand professional characteristics, professional diversion policies and procedures, and ensure that students can choose their favored major as much as possible.

\section{B. Teaching satisfaction influences professional commitment and professional involvement}

Teaching satisfaction can directly influence professional ideal commitment, continuous commitment and professional involvement, and its influence effect on ideal commitment and professional involvement are about 0.375 , as is the main influencers of students' professional commitment and professional involvement.

Students expect their teachers to dedicate to work with rich professional knowledge and practical experience, care about students, arouse their learning interests, even help them form sound knowledge structure, so when recruiting or evaluating teachers, it is suggested to avoid only scientific research focus, professional background, knowledge expertise, personalized teaching ideas, practical teaching skills, engagement and the capacity to stimulate students' interests should all be considered to create an active, engaged and co-created teaching environment.

\section{Course setting satisfaction has positive influence on students' professional commitment}

Course setting directly decides students' professional knowledge contents and structures learned thereby, the course setting satisfaction will directly influence students' learning interests and impetus to some extent, and if the course setting is unsatisfactory, it will easily shake college students' professional commitment and professional involvement. Thus, colleges should regard the actual improvement of students' professional skills as the guidance for the professional courses setting, strive to set courses meeting professional knowledge structure requirements, reasonably set course sequence, update timely, increase and decrease certain courses, meet the social demands, and stimulate students' learning impetus and enthusiasm.

\section{ACKNOWLEDGMENT}

About the author: Jinmei TIAN, the Lecturer of the School of Economics and Management, Shanghai Polytechnic University, mainly engaged in service management reserach, tiancle@126.com;

Corresponding author: Wene QI, the Associate Professor of the College of Economics and Management, SCAU, mainly engaged in agricultural product marketing, service marketing research, qiwene@scau.edu.cn.

This article is subsidized by SCAU Educational Reform Topic (Project No.: JG12075) and 2011 Provincial University Discipline Construction,Teaching Quality and Teaching Reform Engineering Project (YCJ [2011] No. 473).

\section{REFERENCES}

[1] Allen N. J. and J. P. Meyer. The Measurement and Normative Commitment to the Organization [J]. Journal of Occupational Psychology, 1990, (63): 1-18.

[2] Baron, R. M., and D.A. Kenny. The moderator-mediator variable distinction in social psychological research: Conceptual, strategic, and statistical considerations [J]. Journal of personality and social psychology, 1986, 51(6): 1173.

[3] Rong LIAN, Lixian YANG, Lanhua WU. Relationship between Professional Commitment and Learning Burnout of College Students and Scales Developing [J]. Acta Psychologica Sinica, 2005, 37(5): 632636.

[4] Wene QI, Langhu YE. Impact of Teaching Fairness on Teaching Quality and Satisfaction [J]. Journal of Hebei University of Economics and Business (Comprehensive Edition), 2011, (11): 98-101.

[5] Bin WU, Yuhong JIN. Research about Colleges Implementing Enrollment in broad categories of Specialties [J]. Scientific Research [G], 2011, (3): 1759-1762.

[6] Lishan XIE, Xiaoyun HAN, Yun GU. The Impact of Service Justice, Service Quality and Organizational Image on Visitors' Behavior Intention--- an Empirical Study on Museum Service [J]. Tourism Tribune, 2007, 12(22): 51-58.

[7] Wei ZHANG, Cunkuan WANG, and Fang YU. Study on Professional Commitment Level of College Students under Broad Categories Cultivation Mode [J]. Journal of Taiyuan Urban Vocational College, 2014, (10): 80-81. 